\title{
Research on Training Mode of Innovative Talents for Professional Degree Graduates
}

\author{
Yingxin Liu \\ Graduate school Shenyang University \\ Shenyang, China \\ yingxin888@126.com
}

\begin{abstract}
To construct innovative talents training models for professional degree graduates, the paper analyzes the problems existing in professional degree education at present, combining experience and investigating, and puts forward the countermeasures from the aspects of curriculum system, practice base, tutor team, and teaching links.
\end{abstract}

Keywords—professional degree, graduate education, innovative talents, training model

\section{INTRODUCTION}

In 1991, China set up its first professional degree called Management Business Administration (MBA). From then on, the experimentation and development of exploring training model of professional degree graduate education has been undergoing for more than 20 years. Since 2009, most of professional degrees graduates have started full-time training[1]. The professional degree mentioned in this article refers to a full-time master degree. At present, professional degree graduate education in China is in the stage of key development and rapid improvement. The categories of professional degree have increased from 19 degrees in 2010 to 40 degrees today[1]. Professional degree is regarded as an important form of graduate education in China. Its goal is to cultivate high-level application-oriented specialists good professional qualities, who have strong ability to solve practical problems and are able to undertake professional skills or management work[2].

The document of "Implementing Opinions on Deepening the Reform of Innovation and Entrepreneurship Education in Higher Education Institutions" was issued by General Office of the State Council in May, 2015. The Implementation Opinion proposes to improve the quality of personnel training as the core, to focus on innovative personnel training mechanisms, to perfect conditions and policy support, and to promote closer integration of higher education with science and technology, economy and society, in order to accelerate the cultivation of innovation and entrepreneurship talent team with large scale, innovative spirits and courage to devote themselves to the practice[3]. As the highest-level education, postgraduate education shoulders the important mission of cultivating innovative talents, especially, pays more attention to the development of innovation capabilities of postgraduates in professional degrees.

\section{Problems of Professional Degree Graduate Education At The Present Stage}

Professional degree graduate education in colleges and universities usually combines with the actual situation to formulate a training program that meets professional degree graduate education in their own universities. The professional master's degree is a new master's degree added by the state to overcome the shortage of academic masters, and it is to cultivate the application talents that are in short supply in the market. However, due to the in-depth influence of training model of the academic graduate, there still exists some problems with professional degree graduate education in China, which are mainly manifested in the following aspects.

\section{A. Insufficient Awareness of Professional Degree Graduate Training and Lack of Practicality in Curriculum}

The Academic Degrees Committee of the State Council issued the "General Plan for Master's and Ph.D. Professional Degree Graduate Education Development" in November, 2010 and defined the basic concept of professional degree. The professional degree is a degree type set to train high-level application-oriented specialized talents with the rapid development of modern science and technology and society. Professional degree graduates would have strong professional abilities and professional qualities, and they can creatively engage in practical work in accordance with the needs of the specific career fields in society[4]. Although the training program for professional degree graduates has repeatedly emphasized teaching methods such as case teaching and onsite teaching, classroom teaching and extracurricular practice cannot be closely combined with these methods. In the actual training process, "re-lecturing, less discussion" and "re-theory, less practice", the education model is invariable. The innovation of the training mode of professional degree graduates needs to be guaranteed by the concept, system and policy.

\section{B. The Practice Bases Inside and Outside Schools Cannot Really Play a Role, and the Practical Links Lack Effectiveness}

The major resources for academic degree graduate education are in higher institutions or research institutes. In contrast, the most important resource for professional degree graduate education is in various practice fields. In November, 
2013, the document of "Opinions on Further Promoting the Reform of the Professional Graduates' Training Model"issued by the Ministry of Human Resources and Social Security and the Ministry of Education put forward specific opinions on the training mode for innovation of professional degree graduates and pointed out in particular that "encourage to increase cooperation between schools and enterprises. ... to build a multi-dimensional cooperative training model of talent cultivation, scientific research, and social services, etc.[5]. When contacting with companies, professional teachers are more concerned with solving students' internship problems. It has not truly reached a win-win model for jointly cultivating talents with enterprises. Without a perfect practice teaching system, students' ability of innovating, practicing and solving problems has not been improved.

\section{The Implementation of the "Dual-Tutor" System Has not Been Achieved, and the Mentor Team Lacks Continuity.}

"By the year 2020, the realization of graduate education in China has shifted from the cultivation of academic talents to the training of academic talents and applied talents, and the professional degree education system has been substantially improved"[4]. It is also the direction of graduate education efforts and development in recent years. The cultivation of applied talents requires a faculty team that can adapt to professional degrees graduates education. However, the reality is that the theoretical guidance of teachers on campus is the main position. The vast majorities of teachers have little practical experience and lack training experience in professional degrees graduates. Usually, in order to make up for the lack of practical experience of academic teachers in universities and colleges, professional degree graduate education adopts a dual-tutor system. However, in practice, the tutors outside universities are busier with their own affairs and are less instructive about graduates. The "dual-tutor" system is often the form in the process of implementation.

\section{Traditional Teaching Is Still the Main Method in the Training Process and Students Lack Initiative.}

The Ministry of Education and the Ministry of Finance in 2012 jointly launched the "Innovation and Enhancement Capacity Program for Higher Education" (also known as the "2011 Plan"), which explicitly put forward the core tasks of improving uni versity's innovative ability in talents, disciplines, and scientific research[6]. Among them, the "talent" element serves as the primary goal for the realization of the Trinity's innovation capability. At present, strict enrolment and loose graduation is training model of graduate education. Most graduate students passively accept and understand knowledge taught by the teachers. They only use the knowledge and literature materials to obtain answers, but they cannot use their own exploration and research to find and solve problems. On one hand, students lack competitive awareness. On the other hand, the combination of school and enterprise is not close, and scientific research atmosphere is not strong. So, there is not a good soil cultivation of innovation ability.

\section{The Construction of InNovative Talents Training Mode of Professional Degree Graduates}

The postgraduate innovative education refers to the education that has always been carried out in the process of students' cultivation to improve graduate students' innovation consciousness, innovation spirit, innovation ability, and innovative thinking. The innovative ability of graduate students mainly includes[7]: (1) scientific research and innovation capabilities, scientific research is an innovative activity and the core of scientific research capabilities; (2) the ability to identify and solve problems, finding problems is the logical starting point for scientific research, and it is also the focus of training graduate students scientific research capabilities. The solution to the problem is to comprehensively use its own knowledge and ability to find the answer to the problem and then improve scientific research capabilities; (3) document retrieval and data processing capabilities by internet; (4) academic exchange activities.

To adapt to society and enterprises demand as the guidance, to promote the professional development of professional degree graduates as a driving force, to improve the practical ability, application ability and innovation of professional postgraduates as the core, is to foster high-level, high-skilled application talents. Training professional degree graduate innovative talents must establish co-cultivation mode of "dualsubject (school and enterprise)", "dual combination (internal and external combination, professional knowledge and practice project combination)", and "dual mentors (school tutor and external)".

\section{A. To Re-Identify the Values of Professional Degrees Graduate Education and Gradually Improve the Curriculum Training System}

In curriculum structure, we focus on the combination of theory and practice, breadth and depth, knowledge and ability, increase the number and types of elective courses, encourage graduates to take interdisciplinary courses, increase the proportion of elective courses, provide more choices for professional degree graduates, and promote diversity, personalized development. Graduates enhance their enthusiasm and initiative by choosing the curriculum that adapt to their own needs. Therefore, we must take professional needs as the goal in curriculum setting, take practical application as the starting point, pay attention to the improvement of comprehensive knowledge with theoretical knowledge and application ability, and meet the needs of innovative research. At the same time, it is necessary to build an online course of public courses and basic professional courses that meets the characteristics of the school. Online courses can gradually realize the networkization of the courses so that the students will arrange their course rationally without restriction of time and space. Elective courses should reflect the "new" features, which can be the frontier professional development overview, the latest English literature reading, also new dynamics and new development reports in related fields given by famous scholars at home and abroad. 
B. To Give Full Play to the Important Role of the Practice Bases Inside and Outside the School and Continue to Build a Practical Teaching Base

Practice is the birthplace of innovation. The school's practical bases rely on various types of scientific research platforms based on provincial and ministerial key laboratories, which carry out case studies, workshop practice, simulations, etc. to cultivate students' capabilities of practice, research and innovation, and to improve the ability of professional degree graduates to analyze problems and solve practical problems. Practice bases in school cannot fully satisfy the students' desire for advanced knowledge of the enterprise. Therefore, colleges and universities must actively explore the potential of the off-campus practice bases. The off-campus bases are not only for promotion, but also be a training platform for training skilled talents to meet market demands. Off-campus practice bases must strive for strong support from local governments and enterprises and institutions. With the increase in the number of students, the management system of practice bases inside and outside schools, and the evaluation system for student internships, etc., must be constantly adjusted and reformed, and long-term mechanism of teaching practice should be established with practice bases.

\section{To Build Actively the Teachers' Team for Professional Degree Graduate Education, and Construct Effectively a "Double Tutor" Model}

The core of the construction of innovative talents training model is to establish a faculty for professional degree graduate education. Professional degree graduate tutors are mainly academic tutors. The guiding process is biased towards academic research. Therefore, it is necessary to pay attention to the cultivation of existing professional degree graduate instructors' practical abilities. They can learn and practice in the companies. Professional personnel are invited to provide training or lectures for them, so that the team not only has a solid theoretical level, but also has some practice experience and practical ability. Off-campus tutors are a new force for cultivating professional masters who are necessary supplements for school tutors. They have rich practical experience and understand the needs of companies and society for talents. The construction of good tutor team is positive for the development of professional masters. To guarantee effective implementation of the dual-tutor system requires the support and provision of the policy from universities. At the same time, the school tutors, external tutors and postgraduate students must have more communicate with each other, so as to achieve the consistency of the training objectives. Communicate and collision can bring out new ideas and problems.

\section{To Design Elaborately Multi-Level Practical Teaching Links, and Strive to Create a Competitive Incentive Atmosphere}

In the training process, teachers adopt teaching methods that should give full play to postgraduates' initiative, to consciously cultivate postgraduates' thinking ability, to improve the ability to solve problems and analyze problems, stimulate innovation and inspiration. The multi-level practice links can be used in teaching, which mainly include four levels: basic experiment, professional series experiments, research experiments, and practical research with companies[8]. The experimental links at all levels are progressive and the combination of theory and practice runs through the entire period of professional degree graduates study. We can create competition and incentive mechanisms, and establish elimination system, which promote greatly the cultivation of postgraduates' innovative ability and guarantee effectively the quality of postgraduate education.

\section{SUMMARY}

The innovative talents cultivation of professional degree graduate is an important part of the national innovation system. Colleges and universities should actively and comprehensively explore the cultivation mode for improving postgraduates' innovation ability, and train more innovative talents in practice continuously. We must take the initiative in overcoming some difficulties faced by professional degree graduates creative education at this stage so that our professional degree graduate education can play its important role.

\section{REFERENCES}

[1] Zou Yan, Shi Huamei, Zhou Na. Analysis on Factors Influencing Professional Masters' Innovation Capability[J]. The Science Education Article Collects, 2018, 1: 42-44.

[2] National Medium-and Long-Term Plan for Education Reform and Development Planning Program. 2010.7.

[3] Implementing Opinions on Deepening the Reform of Innovation and Entrepreneurship Education in Higher Education Institutions. 2015.5.

[4] Notice on Printing and Distributing the "Overall Program for Postgraduate Education Development for Master and Doctoral Degrees" 2010.10.

[5] Opinions on Deepening Postgraduate Education Reform. 2013.3.

[6] Higher Education Innovation Capacity Improvement Plan. 2012.3.

[7] Luo Zey i, Ning Fangyan, Liu Xiaoguang. Similarities and differences of training models of professional degree programs and academic degree programs from the perspective of innovation ability development [J]. Journal of Graduate Education, 2016, 2(32): 43-46.

[8] Gu Yuehua, Ye Bingliang. The construction of the training mechanis $m$ of innovation practice ability of professional degree graduates [J]. Educational criticism, 2016, 2: 104-106. 